\title{
Mild hyponatremia is associated with low skeletal muscle mass, physical function impairment, and depressive mood in the elderly
}

Chisato Fujisawa ${ }^{1,2,3^{*}}$ (D), Hiroyuki Umegaki ${ }^{1}$, Taiki Sugimoto ${ }^{2}$, Satoshi Samizo ${ }^{1}$, Chi Hsien Huang ${ }^{1}$, Haruki Fujisawa ${ }^{4}$, Yoshihisa Sugimura ${ }^{4}$, Masafumi Kuzuya ${ }^{1}$, Kenji Toba ${ }^{2}$ and Takashi Sakurai ${ }^{1,2}$

\begin{abstract}
Background: Mild hyponatremia (serum sodium 130-135 mEq/L) is a common electrolyte disorder in the elderly. However, its association with both sarcopenia and cognitive function remains to be clarified. Therefore, here we investigated the association of mild hyponatremia with skeletal muscle mass, physical function, and cognitive function in the elderly.

Methods: We enrolled 75 participants with mild hyponatremia and 2907 with normonatremia (serum sodium, 136$145 \mathrm{mEq} / \mathrm{L}$ ) aged $\geq 70$ years who visited the Memory Disorder Outpatient Center of Japan's National Center for Geriatrics and Gerontology. Skeletal muscle mass index (SMI), grip strength (GS), walking speed (WS), one-leg standing (OLS) test times, and neuropsychological test scores were determined.

Results: One-way analysis of covariance showed that elderly participants with mild hyponatremia had lower SMI $\left(7.1 \pm 0.2,7.2 \pm 0.2 \mathrm{~kg} / \mathrm{m}^{2}, p=0.04\right)$, weaker GS (19.1 \pm 1.9 vs $\left.21.4 \pm 1.8 \mathrm{~kg}, p=0.01\right)$, slower WS $(0.9 \pm 0.1$ vs $1.1 \pm 0.1$ $\mathrm{m} / \mathrm{s}, p=0.001)$, and higher GDS- 15 score $(6.4 \pm 0.9$ vs $5.2 \pm 0.9, p=0.002)$ than those with normonatremia. Multiple logistic regression analysis indicated that mild hyponatremia was independently associated with sarcopenia (odds ratio [OR]: $2.2, p=0.02$ ), slower WS (OR: 5.3, $p=0.04)$ and shorter OLS time (OR: $2.5, p=0.02)$ as well as with severe depressive mood (OR: $2.6 p=0.006)$ but not with SMI (OR: 1.6, $p=0.2)$ or GS (OR: 1.9, $p=0.09$ ).
\end{abstract}

Conclusions: Our results suggest that elderly people with even mild hyponatremia had physical function impairment and depressive mood.

Keywords: Balance impairment, Electrolyte disorder, Grip strength, Depression, Gait instability, Hyponatremia

\footnotetext{
* Correspondence: peachisato@med.nagoya-u.ac.jp

'Departments of Community Healthcare and Geriatrics, Graduate School of

Medicine, Nagoya University, 65 Tsurumai-cho, Showa-ku, Nagoya City, Aichi 466-8550, Japan

${ }^{2}$ Center for Comprehensive Care and Research on Memory Disorders,

National Center for Geriatrics and Gerontology, Obu, Japan

Full list of author information is available at the end of the article
}

(c) The Author(s). 2020 Open Access This article is licensed under a Creative Commons Attribution 4.0 International License, which permits use, sharing, adaptation, distribution and reproduction in any medium or format, as long as you give appropriate credit to the original author(s) and the source, provide a link to the Creative Commons licence, and indicate if changes were made. The images or other third party material in this article are included in the article's Creative Commons licence, unless indicated otherwise in a credit line to the material. If material is not included in the article's Creative Commons licence and your intended use is not permitted by statutory regulation or exceeds the permitted use, you will need to obtain permission directly from the copyright holder. To view a copy of this licence, visit http://creativecommons.org/licenses/by/4.0/ The Creative Commons Public Domain Dedication waiver (http://creativecommons.org/publicdomain/zero/1.0/) applies to the data made available in this article, unless otherwise stated in a credit line to the data. 


\section{Background}

Hyponatremia is the most common electrolyte disorder in the elderly. It occurs in about $7 \%$ of all otherwise healthy people aged 55 years or more, with incidence increasing significantly with age. Hyponatremia in the elderly has many causes, including use of medication such as diuretics and antidepressants, syndrome of inappropriate antidiuretic hormone secretion, malnutrition, and comorbidities such as cardiac disease [1]. In most cases though, the symptoms of hyponatremia are mild and related symptoms are subtle, so it often goes unnoticed by patients and physicians.

However, recent studies suggest that asymptomatic hyponatremia is associated with poor prognosis in the elderly. Largely asymptomatic mild-to-moderate hyponatremia was reported to be associated with gait instability, falls, and fractures [2-4]. Also, even after considering the many etiologies of hyponatremia that may contribute to poor prognosis among the elderly, hyponatremia itself is considered to be an independent risk factor for poor prognosis [2]. Attention deficit has also been reported in both humans and rats with mild-to-moderate hyponatremia $[3,5]$. Thus, it seems plausible that asymptomatic hyponatremia contributes to poor prognosis through, for example, falls or fractures probably as a result of impaired attention, posture, and gait.

To date, most studies on the association between physical function and hyponatremia have involved patients with moderate hyponatremia (serum sodium $[\mathrm{SNa}]<130$ $\mathrm{mEq} / \mathrm{L}$ ) [3]. So, it remains unclear whether there is an association between mild hyponatremia (SNa 130-135 $\mathrm{mEq} / \mathrm{L})$, which constitutes most cases of hyponatremia, and both physical and cognitive function in the elderly. In clinical practice, physicians are often hesitant to treat asymptomatic mild hyponatremia with $\mathrm{SNa} \geq 130 \mathrm{mEq} / \mathrm{L}$. However, increased mortality has been reported in patients hospitalized with even mild hyponatremia ( $\mathrm{SNa}$ 130-134 mEq/L) [6]. Thus, we hypothesized that elderly people with even mild hyponatremia, not just those with mild-to-moderate hyponatremia, have physical or cognitive dysfunction such as impaired balance or executive dysfunction. We also hypothesized that there is an association between mild hyponatremia and lower skeletal muscle mass (SMM) in this population based on a report that found an association between chronic hyponatremia and decreased SMM in rats [7].

Because homeostatic responses to environmental challenges decline with aging, hyponatremia is frequently diagnosed in the elderly. We anticipate that more frail elderly patients will present with mild hyponatremia into the future as society ages. Thus, if elderly people with mild hyponatremia tend to have physical or cognitive dysfunction, then we should consider ways to prevent and manage this condition. In this study, we investigated the association of mild hyponatremia with SMM, physical function, and neuropsychological test scores in the elderly.

\section{Methods \\ Participants}

We enrolled 2962 elderly participants with normonatremia (SNa 136-145 mEq/) and 75 with hyponatremia (SNa $130-135 \mathrm{mEq} / \mathrm{L}$ ) aged $\geq 70$ years who visited the National Center for Geriatrics and Gerontology (NCGG) for assessment of memory disorder between September 2010 and November 2017. None of the participants had any severe symptoms such as nausea, vomiting, confusion, or seizures, and all were able to carry out at least 1 of the following 3 physical function tests: grip strength (GS), walking speed (WS), and the one-leg standing (OLS) test. To eliminate pseudohyponatremia and the effect of disease on physical or cognitive function, the following inclusion criteria were adopted: (1) no history of stroke; (2) no pseudohyponatremia ( $\mathrm{TP} \leq 8.0$, Glu $\leq$ 400, $\mathrm{TH}<500$, and $\mathrm{T}$-cho $\leq 280$ ); and (3) not taking medication for Parkinson's disease (e.g., L-dopa, dopamine agonist, trihexyphenidyl, and amantadine).

The study was approved by the NCGG Ethics Committee. All participants provided informed consent before enrollment in the study.

\section{Clinical measures}

The following self-reported and caregiver-reported measures were obtained based on previous studies $[3,4,6,8,9]$ : age, sex, and years of education, alcohol consumption, body mass index (BMI), history of cardiac disease, diabetes, liver disease, lung disease, depression, chronic kidney disease (CKD), cancer, dementia diagnosis, joint pain, visual impairment, hearing impairment, diuretic use, antibiotics use (e.g., clarithromycin, levofloxacin, and minocycline hydrochloride), proton pump inhibitor use, non-steroidal antiinflammatory drug (NSAID) or acetaminophen use, antiepileptic use (e.g., sodium valproate, and carbamazepine), antipsychotic use (e.g., risperidone, haloperidol, and aripiprazole), noradrenergic and specific serotonergic antidepressant (NaSSA) use, selective serotonin reuptake inhibitor (SSRI) or serotonin noradrenaline reuptake inhibitor (SNRI) use, benzodiazepine use (e.g., alprazolam, brotizolam, etizolam, and flunitrazepam), and frequency of physical activity. Those who consumed $>60.0$ g/day of alcohol were defined as heavy drinkers. No exercise per week was defined as inactivity. Potassium, calcium, brain natriuretic peptide, estimated glomerular filtration rate, Creactive protein (CRP), hemoglobin $(\mathrm{Hb})$, thyroidstimulating hormone, and vitamin B12 were checked from their blood samples. Anemia was defined their serum $\mathrm{Hb}$ was $<11.0 \mathrm{~g} / \mathrm{dL}$. Hypothyroidism was defined as a serum thyroid-stimulating hormone level of $10 \mu \mathrm{IU} / \mathrm{mL}$ or less. 
Vitamin B12 deficiency was defined as a serum vitamin B12 level of $<200 \mathrm{pg} / \mathrm{mL}$.

\section{Assessment of SMM, physical function, and sarcopenia} Body weight and SMM were assessed using a multifrequency body composition analyzer (MC-180 MultiFrequency Body Composition Analyzer; Tanita, Tokyo, Japan), which is a scale that uses bioelectrical impedance analysis to determine body composition. We calculated BMI (body weight $[\mathrm{kg}] /$ height squared $\left[\mathrm{m}^{2}\right]$ ) and SMM index (SMI; i.e., SMM $[\mathrm{kg}] /$ height squared $\left[\mathrm{m}^{2}\right]$ ). Low SMM was defined as $\mathrm{SMI}<7.0 \mathrm{~kg} / \mathrm{m}^{2}$ in men and $<5.7$ $\mathrm{kg} / \mathrm{m}^{2}$ in women [10].

Physical function was assessed by measuring GS, WS, and OLS time. Muscle strength was from upper extremity strength measured with a digital force gauge (ZP 500 $\mathrm{N}$; Imada, Toyohashi, Japan) [11]. The best GS (kg) was determined, with low muscle strength defined as $<28 \mathrm{~kg}$ in men and $<18 \mathrm{~kg}$ in women, in accordance with the Asian Working Group for Sarcopenia (AWGS) criteria [10]. Velocity was determined by measuring normal WS, with poor physical performance defined as $\mathrm{WS}<1.0 \mathrm{~m} / \mathrm{s}$ [10]. Postural function was assessed using the OLS test, which measures the time in seconds (up to a maximum of $60 \mathrm{~s}$ ) that participants can stand unassisted on one leg for as long as possible with their eyes open. The best score was used for the analysis [8]. Impaired postural function was defined as OLS time $<15 \mathrm{~s}$ according to the locomotive syndrome criteria [12]. Sarcopenia was defined as low SMM, low muscle strength, and/or low physical function [10].

\section{Assessment of cognitive function}

Cognitive function was assessed with the Mini-Mental State Examination (MMSE) [13], executive function with the Frontal Assessment Battery (FAB) [14], working memory with the Digit Span subtest (forward and backward) of the Wechsler Adult Intelligence Scale [15], attention with the category fluency subtest of the Hasegawa Dementia Rating Scale-Revised [16], and memory with the Logical Memory II subtest of the Wechsler Memory Scale-Revised (WMS-R) [17].

Cognitive impairment was indicated by MMSE score $\leq$ 23, FAB score $\leq 11$ [18], Digit Span forward score $\leq 5$, Digit Span backward score $\leq 3$, category fluency test score $\leq 5$, and WMS-R Logical Memory II subtest raw score $\leq 8$ for $>16$ years of education, $\leq 4$ for $8-15$ years of education, and $\leq 2$ for $0-7$ years of education [19]. Depressive mood was assessed using the Geriatric Depression Scale 15 (GDS-15) [20], with a score $\geq 10$ indicating severe depressive mood [21]. All of the cognitive test results were reviewed by neuropsychologists.

\section{Statistical analysis}

The Chi-squared test and Mann-Whitney's U test were used to investigate differences in characteristics between mild hyponatremia and normonatremia. One-way analysis of covariance (ANCOVA) was used to identify significant differences between the 2 groups in SMI, the 3 physical function test scores, and all the neuropsychological test scores after controlling for covariates. Then, multiple logistic regression analysis was conducted to examine the correlation between mild hyponatremia and sarcopenia, SMI, physical function test scores, and all the neuropsychological test scores. Cutoff scores for these dependent variables were based on the studies mentioned above. All the variables whose $p$-value was $<0.2$ in Table 1 were selected as covariates for both ANCOVA and multiple regression analysis as shown under Tables 3 and 4 . All analyses were performed using SPSS Statistics for Windows ver. 26.0 (IBM Corp., Armonk, NY). A p-value $<0.05$ was considered significant.

\section{Results}

During the study period, 7580 individuals aged $\geq 70$ years visited the NCGG Memory Disorder Outpatient Center. Of them, 3097 met the inclusion criteria: 8 had moderate or more severe hyponatremia $(\mathrm{SNa}<130 \mathrm{mEq} / \mathrm{L}), 75$ had mild hyponatremia (SNa 130-135 mEq/L), 2907 had normonatremia (SNa 136-145 mEq/L), and 107 had hypernatremia $(\mathrm{SNa}>145 \mathrm{mEq} / \mathrm{L})$. Thus, 75 participants with mild hyponatremia and 2907 with normonatremia were included in this study.

The characteristics of hyponatremia and normonatremia are summarized for all participants in Table 1 . The mild hyponatremia group had significantly older age (median [interquartile range], 82.0 [76.0-84.0] vs 79.0 [75.0-83.0] years), fewer women (48.0\% vs $63.1 \%)$, higher prevalence of history of diabetes $(48.0 \%$ vs $36.1 \%)$, higher antiepileptic use (2.7\% vs $0.4 \%)$, higher SSRI or SNRI use (6.7\% vs $1.8 \%)$, higher benzodiazepine use $(16.0 \%$ vs $8.7 \%)$, higher potassium (4.4 [4.1-4.6] vs $4.2[2.9-4.4] \mathrm{mEq} / \mathrm{L})$, higher CRP $(0.07$ [0.04-0.2] vs $0.05[0.03-0.1] \mathrm{mg} / \mathrm{dL})$, and higher frequency of anemia (13.3\% vs $6.7 \%)$ and hypothyroidism ( $2.7 \%$ vs $0.3 \%)$ compared with the normonatremia group. As shown in Table 2, the mild hyponatremia group also had more cases of sarcopenia, weaker GS, slower WS, shorter OLS time, and higher GDS-15 score.

ANCOVA showed that mild hyponatremia had a significant effect on SMI $(F[1,2393)=4.2 ; p=0.04)$, GS $(F$ $[1,1951]=6.6 ; p=0.01)$, WS $(F[1,672]=11.9 ; p=$ $0.001)$, and GDS-15 score $(F[1,2883]=9.7 ; p=0.002)$ after controlling for covariates, and a nearly significant effect on OLS time $(F[1,2527]=3.6 ; p=0.06)$ (Table 3$)$.

The results of multiple logistic regression using each cutoff score are shown in Table 4. After entering all 
Table 1 Participant characteristics

\begin{tabular}{|c|c|c|c|c|c|}
\hline & $\mathrm{n}$ & Mild hyponatremia group & $\mathrm{n}$ & Normonatremia group & $p$ \\
\hline Age, years & 75 & $82.0(76.0-84.0)$ & 2907 & $79.0(75.0-83.0)$ & 0.03 \\
\hline Female, n (\%) & 75 & $36(48.0)$ & 2907 & $1833(63.1)$ & 0.008 \\
\hline Education, years & 75 & $9.0(9.0-12.0)$ & 2869 & $9.0(9.0-12.0)$ & 0.8 \\
\hline Heavy drinker ${ }^{a}, \mathrm{n}(\%)$ & 74 & $1(1.4)$ & 2879 & $55(1.9)$ & 0.7 \\
\hline Body mass index, $\mathrm{kg} / \mathrm{m}^{2}$ & 75 & $21.0(19.1-23.6)$ & 2905 & $21.8(19.8-24.0)$ & 0.09 \\
\hline History of cardiac disease, n (\%) & 75 & $15(20.0)$ & 2907 & $365(12.6)$ & 0.06 \\
\hline History of diabetes, n (\%) & 75 & $36(48.0)$ & 2907 & $1049(36.1)$ & 0.03 \\
\hline History of liver disease, n (\%) & 75 & $1(1.3)$ & 2907 & $61(2.1)$ & 0.6 \\
\hline History of lung disease, n (\%) & 75 & $4(5.3)$ & 2907 & $119(4.1)$ & 0.6 \\
\hline History of depression, n (\%) & 75 & $2(2.7)$ & 2907 & $106(3.6)$ & 0.7 \\
\hline History of CKD, n (\%) & 75 & $33(44.0)$ & 2905 & $1006(34.6)$ & 0.1 \\
\hline History of cancer, n (\%) & 75 & $9(12.0)$ & 2907 & $240(8.3)$ & 0.2 \\
\hline Dementia, n (\%) & 75 & $45(60.0)$ & 2907 & $1516(52.1)$ & 0.2 \\
\hline Joint pain, n (\%) & 74 & $31(41.9)$ & 2890 & $1173(40.6)$ & 0.8 \\
\hline Visual impairment, n (\%) & 74 & $37(50.0)$ & 2888 & $1607(55.6)$ & 0.4 \\
\hline Hearing impairment, $\mathrm{n}(\%)$ & 74 & $47(63.5)$ & 2883 & $1524(52.9)$ & 0.07 \\
\hline Diuretics use, n (\%) & 75 & $6(8.0)$ & 2907 & $129(4.4)$ & 0.1 \\
\hline Antibiotics, n (\%) & 75 & $0(0.0)$ & 2907 & $34(1.2)$ & 0.3 \\
\hline Proton pump inhibitor use, n (\%) & 75 & $6(8.0)$ & 2907 & $208(7.2)$ & 0.8 \\
\hline NSAID or acetaminophen use, $\mathrm{n}(\%)$ & 75 & $4(5.3)$ & 2907 & $127(4.4)$ & 0.7 \\
\hline Antiepileptic use, n (\%) & 75 & $2(2.7)$ & 2907 & $11(0.4)$ & 0.003 \\
\hline Antipsychotic use, n (\%) & 75 & $0(0.0)$ & 2907 & $17(58.5)$ & 0.5 \\
\hline NaSSA use, n (\%) & 75 & $1(1.3)$ & 2907 & $6(0.2)$ & 0.05 \\
\hline SSRI or SNRI use, n (\%) & 75 & $5(6.7)$ & 2907 & $51(1.8)$ & 0.002 \\
\hline Benzodiazepine use, n (\%) & 75 & $12(16.0)$ & 2907 & $254(8.7)$ & 0.03 \\
\hline Inactivity, n (\%) & 74 & $21(28.4)$ & 2864 & $957(33.4)$ & 0.4 \\
\hline Potassium, mEq/L & 75 & $4.4(4.1-4.6)$ & 2907 & $4.2(2.9-4.4)$ & $<0.001$ \\
\hline Calcium, mg/dL & 75 & $9.4(9.1-9.7)$ & 2901 & $9.5(9.2-9.8)$ & 0.4 \\
\hline BNP, pg/mL & 38 & $30.1(16.5-64.9)$ & 1562 & $31.8(16.3-60.2)$ & 0.9 \\
\hline $\mathrm{eGFR}, \mathrm{mL} / \mathrm{min} / 1.73 \mathrm{~m}^{2}$ & 75 & $62.1(52.2-80.9)$ & 2905 & $63.3(54.0-73.2)$ & 0.6 \\
\hline $\mathrm{CRP}, \mathrm{mg} / \mathrm{dL}$ & 74 & $0.07(0.04-0.2)$ & 2881 & $0.05(0.03-0.1)$ & 0.02 \\
\hline Anemia ${ }^{\mathrm{b}}, \mathrm{n}(\%)$ & 75 & $10(13.3)$ & 2907 & $195(6.7)$ & 0.03 \\
\hline Hypothyroidism, n (\%) & 75 & $2(2.7)$ & 2898 & $10(0.3)$ & 0.002 \\
\hline Vitamin B12 deficiency ${ }^{\mathrm{d}}, \mathrm{n}(\%)$ & 63 & $1(1.6)$ & 2535 & $59(2.3)$ & 0.7 \\
\hline
\end{tabular}

Values are median (interquartile range) or number (percentage). Differences were assessed using the Kruskal-Wallis test for continuous variables or the Chisquared test for categorical variables

Abbreviations: BNP Brain natriuretic peptide, CRP C-reactive protein, eGFR Estimated glomerular filtration rate, NSAID Non-steroidal anti-inflammatory drug, NaSSA Noradrenergic and specific serotonergic antidepressant, SNRI Serotonin noradrenaline reuptake inhibitor, SSRI Selective serotonin reuptake inhibitors. ${ }^{a}>60 \mathrm{~g} /$ day of alcohol, ${ }^{b}$ Hemoglobin $<11.0 \mathrm{~g} / \mathrm{dL}$, ${ }^{c}$ thyroid-stimulating hormone $\leq 10 \mu \mathrm{lU} / \mathrm{mL}$, ${ }^{\mathrm{d}}$ vitamin $\mathrm{B} 12<200 \mathrm{pg} / \mathrm{mL}$

variables written under Table 4 into multivariable models 2 , the elderly with mild hyponatremia were significantly more likely to have sarcopenia (odds ratio [OR], 2.2; 95\% confidence interval [CI], 1.1-4.4; $p=$ $0.02)$, poor physical performance as indicated by slower WS (OR, 5.3; 95\% CI, 1.1-25.4; $p=0.04$ ), impaired postural balance (OR, 2.5; 95\% CI, 1.2-5.5; $p=0.02)$, and severe depressive mood (OR, 2.6; 95\% CI, 1.3-5.2; $p=$ $0.006)$ and tended to have low muscle mass as indicated by weaker GS (OR, 1.9; 95\% CI; 0.9-3.8; $p=0.09$ ). However, mild hyponatremia was not significantly associated with lower SMI (OR, 1.6; 95\% CI, 0.8-3.2; $p=0.2)$. There was no overfitting, and goodness of fit (Hosmer-Lemeshow test) indicated that each logistic model fit well. 
Table 2 Difference in physical and cognitive function between the groups

\begin{tabular}{|c|c|c|c|c|c|}
\hline & $\mathrm{n}$ & Mild hyponatremia group & $\mathbf{n}$ & Normonatremia group & $p$ \\
\hline Sarcopenia, n (\%) & 52 & $34(65.4)$ & 2110 & $928(44.0)$ & 0.002 \\
\hline $\mathrm{SMI}, \mathrm{kg} / \mathrm{m}^{2}$ & 51 & $6.4(5.7-6.9)$ & 2418 & $6.4(5.7-7.2)$ & 0.5 \\
\hline \multicolumn{6}{|l|}{ Physical function tests } \\
\hline Grip strength, kg & 48 & $17.7(12.9-22.2)$ & 1972 & $19.7(15.2-25.0)$ & 0.04 \\
\hline Walking speed, m/s & 17 & $0.7(0.5-0.9)$ & 704 & $1.0(0.8-1.2)$ & $<0.001$ \\
\hline One-leg standing time, $s$ & 54 & $5.0(2.6-13.1)$ & 2546 & $8.6(3.7-21.9)$ & 0.008 \\
\hline \multicolumn{6}{|l|}{ Neuropsychological tests } \\
\hline MMSE & 75 & $20.0(17.0-25.0)$ & 2901 & $21.0(17.0-25.0)$ & 0.4 \\
\hline$F A B$ & 34 & $9.0(7.0-12.0)$ & 1732 & $10.0(8.0-12.0)$ & 0.6 \\
\hline Digit Span forward & 38 & $5.0(5.0-6.0)$ & 1775 & $5.0(4.8-6.0)$ & 0.9 \\
\hline Digit Span backward & 38 & $3.0(3.0-4.0)$ & 1761 & $3.0(3.0-4.0)$ & 0.8 \\
\hline Category fluency & 75 & $8.0(6.0-10.0)$ & 2899 & $8.0(5.0-10.0)$ & 0.3 \\
\hline Logical memory ॥ & 37 & $3.0(3.0-12.0)$ & 1780 & $3.0(3.0-11.0)$ & 0.3 \\
\hline GDS-15 & 72 & $4.0(2.0-6.0)$ & 2893 & $5.0(3.0-8.0)$ & 0.002 \\
\hline
\end{tabular}

Values are median (interquartile range) or number (percentage). Differences were assessed using the Kruskal-Wallis test for continuous variables or the Chisquared test for categorical variables

Abbreviations: FAB Frontal Assessment Battery, GDS-15 15-item Geriatric Depression Scale, MMSE Mini-Mental state examination, SMI Skeletal muscle mass index

\section{Discussion}

\section{Correlation between mild hyponatremia and SMM and} physical function

The mild hyponatremia group had significantly lower SMI, weaker GS, and slower WS, and nearly significantly shorter OLS time compared with the normonatremia group, even after controlling for covariates. When using the AWGS criteria for sarcopenia, the mild hyponatremia group had a significantly higher risk of sarcopenia and worse physical performance and impaired balance, and a marginally significant higher risk of worse muscle strength but was not at risk of having a lower SMI.
The present study demonstrated that elderly people with even mild hyponatremia had gait disturbances and balance impairment. Previous studies demonstrated that chronic hyponatremia causes gait disturbances in both rats [5] and humans [2]. The mechanism behind these observations is yet to be determined. However, for the mechanism whereby hyponatremia contributes to gait dysfunction and balance impairment, if we look at it from the viewpoint of the central nervous system (CNS), the brain cells adapt to hyponatremia by swelling with the loss of osmolytes, such as glutamate [22], which is a neurotransmitter involved in gait and balance function

Table 3 ANCOVA results for the comparison of skeletal mass index, physical function, and psychological tests between the groups

\begin{tabular}{|c|c|c|c|c|c|c|c|}
\hline & & Mild hyponatremia $\mathrm{g}$ & & Normonatremia grou & & & \\
\hline & $\mathbf{n}$ & Adjusted mean $\pm S D$ & $\mathbf{n}$ & Adjusted mean \pm SD & $\mathbf{F}$ & $p$ & $\eta^{2}$ \\
\hline Skeletal muscle mass index, $\mathrm{kg} / \mathrm{m}^{2}$ & 50 & $7.1 \pm 0.2$ & 2361 & $7.2 \pm 0.2$ & 4.2 & 0.04 & 0.002 \\
\hline Grip strength, kg & 46 & $19.1 \pm 1.9$ & 1923 & $21.4 \pm 1.8$ & 6.6 & 0.01 & 0.003 \\
\hline Walking speed, m/s & 16 & $0.9 \pm 0.1$ & 673 & $1.1 \pm 0.1$ & 11.9 & 0.001 & 0.02 \\
\hline One-leg standing test, s & 53 & $7.5 \pm 4.9$ & 2492 & $11.8 \pm 4.6$ & 3.6 & 0.06 & 0.001 \\
\hline Mini-Mental State Examination & 73 & $20.3 \pm 1.5$ & 2839 & $20.5 \pm 1.4$ & 0.06 & 0.8 & $<0.001$ \\
\hline Frontal Assessment Battery & 33 & $7.5 \pm 1.2$ & 1689 & $7.5 \pm 1.1$ & 0.001 & 0.99 & $<0.001$ \\
\hline Digit Span forward & 37 & $4.7 \pm 0.4$ & 1732 & $4.8 \pm 0.4$ & 0.4 & 0.5 & $<0.001$ \\
\hline Digit Span backward & 37 & $2.2 \pm 0.4$ & 1718 & $2.2 \pm 0.4$ & 0.002 & 0.96 & $<0.001$ \\
\hline Verbal fluency & 73 & $7.7 \pm 0.6$ & 2838 & $7.5 \pm 0.6$ & 0.003 & 0.95 & $<0.001$ \\
\hline Logical memory $\|$ & 36 & $4.8 \pm 5.7$ & 1737 & $3.7 \pm 5.2$ & 0.2 & 0.7 & $<0.001$ \\
\hline 15-item Geriatric Depression Scale & 71 & $6.4 \pm 0.9$ & 2830 & $5.2 \pm 0.9$ & 9.7 & 0.002 & 0.003 \\
\hline
\end{tabular}

$\eta^{2}$, the effect size

Covariates adjusted for were age, sex, body mass index, history of heart disease, diabetes, CKD, hearing impairment, diuretic use, antiepileptic use, NaSSA use, SSRI or SNRI use, benzodiazepine use, serum potassium, C-reactive protein, anemia, and hypothyroidism

Abbreviations: SD Standard deviation 
Table 4 Results of logistic regression analysis for predicting sarcopenia, skeletal muscle mass, and physical and cognitive functions

\begin{tabular}{|c|c|c|c|c|c|c|}
\hline \multirow[t]{2}{*}{ Dependent variables } & \multicolumn{3}{|c|}{ Model 1} & \multicolumn{3}{|c|}{ Model 2} \\
\hline & $\mathbf{n}$ & OR $(95 \% \mathrm{Cl})$ & $p$ & $\mathbf{n}$ & OR $(95 \% \mathrm{Cl})$ & $p$ \\
\hline Sarcopenia & 2244 & $2.2(1.2-4.0)$ & 0.008 & 2107 & $2.2(1.1-4.4)$ & 0.02 \\
\hline Low skeletal muscle mass index ${ }^{a}$ & 2561 & $1.7(1.0-3.0)$ & 0.07 & 2411 & $1.6(0.8-3.2)$ & 0.2 \\
\hline Low muscle strength ${ }^{b}$ & 2097 & $2.2(1.1-4.4)$ & 0.03 & 1968 & $1.9(0.9-3.8)$ & 0.09 \\
\hline Poor physical performance; Walking speed $<1 \mathrm{~m} / \mathrm{s}$ & 747 & $3.5(1.0-13.0)$ & 0.06 & 689 & $5.3(1.1-25.4)$ & 0.04 \\
\hline One-leg standing test $<15 \mathrm{~s}$ & 2695 & $2.3(1.1-4.8)$ & 0.03 & 2541 & $2.5(1.2-5.5)$ & 0.02 \\
\hline Cognitive disturbance; MMSE $<24$ & 3091 & $1.1(0.7-1.9)$ & 0.6 & 2912 & $1.1(0.7-1.9)$ & 0.7 \\
\hline Executive dysfunction; $F A B<12$ & 1831 & $1.0(0.5-2.3)$ & 0.95 & 1722 & $0.9(0.4-2.1)$ & 0.8 \\
\hline Poor walking memory; Digit Span forward $<6$ & 1883 & $0.9(0.5-1.9)$ & 0.8 & 1769 & $0.9(0.4-1.9)$ & 0.8 \\
\hline Poor walking memory; Digit Span backward $<4$ & 1869 & $1.1(0.5-2.1)$ & 0.8 & 1755 & $1.0(0.5-2.1)$ & 0.96 \\
\hline Poor attention; the category fluency subtest of the HDS-R $<6$ & 3088 & $1.1(0.6-1.8)$ & 0.8 & 2911 & $1.0(0.6-1.7)$ & 0.99 \\
\hline Memory disorder ${ }^{c}$ & 1889 & $0.7(0.3-1.5)$ & 0.4 & 1772 & $0.8(0.4-1.9)$ & 0.7 \\
\hline Severe depression; GDS-15 $\geq 10$ & 3078 & $2.7(1.4-5.2)$ & 0.004 & 2901 & $2.6(1.3-5.2)$ & 0.006 \\
\hline
\end{tabular}

Model 1. Adjusted for age and sex

Model 2. In the binary logistic regression analysis, all variables were entered into the multivariable model (age, sex, body mass index, history of heart disease,

diabetes, CKD, hearing impairment, diuretic use, antiepileptic use, NaSSA use, SSRI or SNRI use, benzodiazepine use, serum potassium, C-reactive protein, anemia, and hypothyroidism)

Abbreviations: CI Confidence interval, CKD Chronic kidney disease, FAB Frontal Assessment Battery, GDS-15 15-item Geriatric Depression Scale, HDS-R Hasegawa Dementia Rating Scale-Revised, MMSE Mini-Mental State Examination, NaSSA Noradrenergic and specific serotonergic antidepressant, OR Odds ratio, SNRI Serotonin noradrenaline reuptake inhibitor, SSRI Selective serotonin reuptake inhibitors, WMS-R Wechsler Memory Scale-Revised

${ }^{a}$ Low skeletal muscle mass was defined as skeletal muscle mass index $<7.0 \mathrm{~kg} / \mathrm{m}^{2}$ in men and $<5.7 \mathrm{~kg} / \mathrm{m}^{2}$ in women

${ }^{\mathrm{b}}$ Reduced grip strength was defined as $<28 \mathrm{~kg}$ for men and $<18 \mathrm{~kg}$ for women

${ }^{c}$ Raw WMS-R II score $\leq 8 / 9$ for $>16$ years of education, $\leq 4 / 5$ for $8-15$ years of education, $\leq 2 / 3$ for $0-7$ years of education

[4]. Rerelease of glutamate from the cytosol to extracellular space contributes to excessive activation of neuronal glutamate receptors, causing excitotoxic cell damage and death in the CNS [23]. However, it remains to be elucidated what severity of hyponatremia, and particularly whether mild hyponatremia, causes these consequences, which could lead to slow WS and balance dysfunction.

On the other hand, we found that muscle strength as measured by GS was significantly different between the mild hyponatremia and normonatremia groups of elderly participants, but when using the AWGS cutoff value for sarcopenia, the logistic regression model showed that the association between mild hyponatremia and GS was not significant. Although Cairns et al. observed a 10\% decrease in muscle strength when the sodium concentration was decreased from 147 to $60 \mathrm{mmol} / \mathrm{L}$ in mice [24], Vandergheynst et al. did not observe any significant difference in GS when the sodium concentration was increased from $127.7 \pm 2.5 \mathrm{mmol} / \mathrm{L}$ to $136.1 \pm 1.8 \mathrm{mmol} / \mathrm{L}$ in humans [25]. Mild hyponatremia itself is correlated with muscle strength, but it's impact on GS may be insufficient to bring the GS under the cutoff point.

Our study revealed that elderly individuals with even mild hyponatremia had poor physical function. A previous study reported that elderly patients with similar severity of hyponatremia were much more sensitive to alterations in gait tests compared with younger patients [26]. These findings imply that elderly individuals with even mild hyponatremia may be at risk of physical dysfunction.

In clinical practice, it is particularly important to know that the elderly with mild hyponatremia have low physical function because, as mentioned above, mild hyponatremia often goes unnoticed by patients and physicians and physicians are often hesitant to treat asymptomatic mild hyponatremia with $\mathrm{SNa} \geq 130 \mathrm{mEq} / \mathrm{L}$. However, a previous study reported a significant improvement in activities of daily living and cognition among geriatric patients effectively treated for hyponatremia [27]. Mild hyponatremia in the elderly deserves more of our attention. Additional longitudinal studies are needed to strengthen the evidence on the severity of hyponatremia that affects physical function in the elderly and the underlying mechanism.

Although we included many covariates, we might have missed some unmeasured or unknown potential confounders. In addition, we did not determine the causes or chronicity of mild hyponatremia. The duration of hyponatremia or severity of comorbidities may be additional risk factors for physical dysfunction or depressive mood. Hyponatremia could be a marker of severity in these unmeasured underlying illnesses and might signal the presence of physiologic derangements or comorbidities.

Regarding low muscle mass in elderly with mild hyponatremia, hyponatremia tended to lead to progressive SMM loss in rats [7]. Hyponatremia has also been often 
observed in patients who are malnourished and in the elderly with sarcopenia [28]. In the present study, although there was no significant difference in BMI between the elderly with mild hyponatremia and those with normonatremia, the elderly with mild hyponatremia might have had low protein intake and/or vitamin $\mathrm{D}$ deficiency. However, the impact of these factors on muscle strength may be insufficient to bring the SMI score under the cutoff point for mild hyponatremia.

\section{Association between mild hyponatremia and depressive mood}

This study also found that mild hyponatremia was associated with depressive mood, but not with other neuropsychological tests scores. To our knowledge, this study is the first to report an association between mild hyponatremia and depressive mood in the elderly. Previously, the efficacy of tolvaptan was evaluated in patients with hyponatremia. Serum sodium concentrations increased more in the tolvaptan group than in the placebo group and a significant improvement was observed in the tolvaptan group on the Mental Component Summary (for vitality, social functioning, emotionally limited accomplishment, calmness, and sadness) of the Medical Outcomes Study 12-item Short-Form General Health Survey [29]. The mechanism has yet to be determined, but some studies have suggested a correlation between depression and glutamate, whose release from brain cells to the extracellular space may be mediated by hyponatremia [30, 31]. Anti-glutamate agents are known to have antidepressant effects in patients with depression [32]. Alternatively, elderly individuals with depressive mood might not have sufficient appetite to consume an appropriate amount of dietary sodium.

\section{Study strengths and limitations}

This study used detailed neuropsychological test results and is the first to reveal a correlation between mild hyponatremia and depressive mood. A strength of the study is its large sample, which may have minimized many possible confounders, including pseudohyponatremia, many types of medication, and past histories.

However, there are also some limitations. Despite the large sample size, few individuals with hyponatremia undertook the physical function tests, especially for WS. This left us with a small sample of mild hyponatremia, which did not allow us to adapt another mild hyponatremia cutoff, such as $134 \mathrm{mEq} / \mathrm{L}$. Next, as mentioned above, we might have missed some unmeasured or unknown potential confounders; for example, we did not obtain enough data about locomotor system disease or endocrine disease to consider their potential effects. Lastly, this is a cross-sectional study and the specific mechanisms underlying the association of mild hyponatremia with physical function and depressive mood remain to be investigated.

\section{Conclusions}

In this study, elderly participants with mild hyponatremia had impaired lower skeletal muscle mass, physical function, and depressive mood compared with elderly participants with normonatremia. Mild hyponatremia in the elderly deserves more attention than it currently receives. Additional longitudinal studies with a larger number of participants with hyponatremia are needed to strengthen the evidence on the severity of hyponatremia that affects physical and cognitive function in the elderly.

\section{Abbreviations}

BMI: Body mass index; Cl: Confidence interval; CNS: Central nervous system; FAB: Frontal Assessment Battery; GDS-15: 15-item Geriatric Depression Scale; OLS: One-leg standing; OR: Odds ratio; MMSE: Mini-Mental State Examination; NaSSA: Noradrenergic and specific serotonergic antidepressant; NSAID: Nonsteroidal anti-inflammatory drug; SMI: Skeletal muscle mass index;

SMM: Skeletal muscle mass; SNRI: Serotonin noradrenaline reuptake inhibitor; SSRI: Selective serotonin reuptake inhibitor; WMS-R: Wechsler Memory ScaleRevised; WS: Walking speed

\section{Acknowledgements}

None.

Authors' contributions

CF, HF, and YS formed the research question. TS1 coded the data. CF conducted the analysis with input from SS, TS2, and CH. CF wrote the manuscript and $\mathrm{HU}, \mathrm{MK}, \mathrm{KT}$, and TS2 reviewed the article. All authors approved the final draft.

\section{Funding}

This study was partially supported by grants from Research Funding of Longevity Sciences (30-1) of the National Center for Geriatrics and Gerontology, Japan. The funding sources were not involved in the study design, collection, analysis, interpretation of data, or writing of the paper.

\section{Availability of data and materials}

The data supporting the conclusion of this article may be made available by the corresponding author upon reasonable request.

\section{Ethics approval and consent to participate}

This study was approved by the ethics committee of the National Center for Geriatrics and Gerontology, Japan (Approval No. 1415). Written informed consent was obtained from all subjects or their legally authorized representatives prior to enrollment in the study.

Consent for publication

Not applicable.

\section{Competing interests}

All authors declare that they have no competing interests, except that Hiroyuki Umegaki is an Associate Editor of BMC Geriatrics.

\section{Author details}

'Departments of Community Healthcare and Geriatrics, Graduate School of Medicine, Nagoya University, 65 Tsurumai-cho, Showa-ku, Nagoya City, Aichi 466-8550, Japan. ${ }^{2}$ Center for Comprehensive Care and Research on Memory Disorders, National Center for Geriatrics and Gerontology, Obu, Japan. ${ }^{3}$ Department of Palliative Medicine, Seirei Hospital, Nagoya, Japan. ${ }^{4}$ Department of Endocrinology and Metabolism, Fujita Health University, Toyoake, Japan. 
Received: 1 August 2020 Accepted: 10 December 2020

Published online: 06 January 2021

\section{References}

1. Filippatos TD, Makri A, Elisaf MS, Liamis G. Hyponatremia in the elderly: challenges and solutions. Clin Interv Aging. 2017;12:1957-65.

2. Decaux G. Is asymptomatic hyponatremia really asymptomatic? Am J Med. 2006;119(7 Suppl 1):S79-82.

3. Renneboog B, Musch W, Vandemergel X, Manto MU, Decaux G. Mild chronic hyponatremia is associated with falls, unsteadiness, and attention deficits. Am J Med. 2006;119(1):8.

4. Ayus JC, Fuentes NA, Negri AL, Moritz ML, Giunta DH, Kalantar-Zadeh K, et al. Mild prolonged chronic hyponatremia and risk of hip fracture in the elderly. Nephrol Dial Transplant. 2016;31(10):1662-9.

5. Fujisawa $H$, Sugimura $Y$, Takagi $H$, Mizoguchi $H$, Takeuchi $H$, Izumida $H$, et al. Chronic Hyponatremia causes neurologic and Psychologic impairments. J Am Soc Nephrol. 2016;27(3):766-80

6. Waikar SS, Mount DB, Curhan GC. Mortality after hospitalization with mild, moderate, and severe hyponatremia. Am J Med. 2009;122(9):857-65.

7. Barsony J, Manigrasso MB, Xu Q, Tam H, Verbalis JG. Chronic hyponatremia exacerbates multiple manifestations of senescence in male rats. Age (Dordr) 2013;35(2):271-88

8. Fujisawa C, Umegaki H, Okamoto K, Nakashima H, Kuzuya M, Toba K, et al. Physical Function Differences Between the Stages From Normal Cognition to Moderate Alzheimer Disease. J Am Med Dir Assoc. 2017;18(4):368 e9-e15.

9. Liamis $\mathrm{G}$, Milionis $\mathrm{H}$, Elisaf M. A review of drug-induced hyponatremia. Am J Kidney Dis. 2008;52(1):144-53.

10. Chen LK, Woo J, Assantachai P, Auyeung TW, Chou MY, lijima K, et al. Asian Working Group for Sarcopenia: 2019 Consensus Update on Sarcopenia Diagnosis and Treatment. J Am Med Dir Assoc. 2020;21(3):300-7.e2. https:// doi.org/10.1016/j.jamda.2019.12.012.

11. Matsui Y, Fujita R, Harada A, Sakurai T, Nemoto T, Noda N, et al. Association of grip strength and related indices with independence of activities of daily living in older adults, investigated by a newly-developed grip strength measuring device. Geriatr Gerontol Int. 2014;14(Suppl 2):77-86.

12. Muramoto A, Imagama S, Ito Z, Hirano K, Tauchi R, Ishiguro N, et al. Threshold values of physical performance tests for locomotive syndrome. J Orthop Sci. 2013;18(4):618-26.

13. Folstein MF, Folstein SE, McHugh PR. "Mini-mental state". A practical method for grading the cognitive state of patients for the clinician. J Psychiatr Res. 1975;12(3):189-98.

14. Dubois B, Slachevsky A, Litvan I, Pillon B. The FAB: a frontal assessment battery at bedside. Neurology. 2000;55(11):1621-6.

15. Wechsler D. Manual for the Wechsler adult intelligence scale, vol. vi. New York: Psychological Corp; 1955. p. 110.

16. Kim KW, Lee DY, Jhoo JH, Youn JC, Suh YJ, Jun YH, et al. Diagnostic accuracy of mini-mental status examination and revised hasegawa dementia scale for Alzheimer's disease. Dement Geriatr Cogn Disord. 2005;19(5-6):324-30.

17. Wechsler D. WMS-R : Wechsler Memory Scale--Revised : manual, vol. viii. San Antonio: Psychological Corp. : Harcourt Brace Jovanovich; 1987. p. 150.

18. Chong MS, Lim WS, Chan SP, Feng L, Niti M, Yap P, et al. Diagnostic performance of the Chinese frontal assessment battery in early cognitive impairment in an Asian population. Dement Geriatr Cogn Disord. 2010;30(6):525-32.

19. Chapman KR, Bing-Canar H, Alosco ML, Steinberg EG, Martin B, Chaisson C, et al. Mini mental state examination and logical memory scores for entry into Alzheimer's disease trials. Alzheimers Res Ther. 2016;8:9

20. Yesavage JA, Brink TL, Rose TL, Lum O, Huang $V$, Adey $M$, et al. Development and validation of a geriatric depression screening scale: a preliminary report. J Psychiatr Res. 1982;17(1):37-49.

21. Wada T, Ishine M, Sakagami T, Okumiya K, Fujisawa M, Murakami S, et al. Depression in Japanese community-dwelling elderly--prevalence and association with ADL and QOL. Arch Gerontol Geriatr. 2004;39(1):15-23.

22. Schober AL, Mongin AA. Intracellular levels of glutamate in swollen astrocytes are preserved via neurotransmitter reuptake and de novo synthesis: implications for hyponatremia. J Neurochem. 2015;135(1):176-85.

23. Arundine M, Tymianski M. Molecular mechanisms of glutamate-dependent neurodegeneration in ischemia and traumatic brain injury. Cell Mol Life Sci. 2004;61(6):657-68

24. Cairns SP, Buller SJ, Loiselle DS, Renaud JM. Changes of action potentials and force at lowered $[\mathrm{Na}+] \mathrm{O}$ in mouse skeletal muscle: implications for fatigue. Am J Physiol Cell Physiol. 2003;285(5):C1131-41.
25. Vandergheynst F, Gombeir Y, Bellante F, Perrotta G, Remiche G, Melot C, et al. Impact of hyponatremia on nerve conduction and muscle strength. Eur J Clin Investig. 2016;46(4):328-33.

26. Renneboog B, Sattar L, Decaux G. Attention and postural balance are much more affected in older than in younger adults with mild or moderate chronic hyponatremia. Eur J Intern Med. 2017;41:e25-e6.

27. Brinkkoetter PT, Grundmann F, Ghassabeh PJ, Becker I, Johnsen M, Suarez V, et al. Impact of resolution of Hyponatremia on neurocognitive and motor performance in geriatric patients. Sci Rep. 2019;9(1):12526.

28. Bertini V, Nicoletti C, Beker BM, Musso CG. Sarcopenia as a potential cause of chronic hyponatremia in the elderly. Med Hypotheses. 2019;127:46-8.

29. Schrier RW, Gross P, Gheorghiade M, Berl T, Verbalis JG, Czerwiec FS, et al. Tolvaptan, a selective oral vasopressin V2-receptor antagonist, for hyponatremia. N Engl J Med. 2006;355(20):2099-112.

30. Auer DP, Putz B, Kraft E, Lipinski B, Schill J, Holsboer F. Reduced glutamate in the anterior cingulate cortex in depression: an in vivo proton magnetic resonance spectroscopy study. Biol Psychiatry. 2000;47(4):305-13.

31. Mauri MC, Ferrara A, Boscati L, Bravin S, Zamberlan F, Alecci M, et al. Plasma and platelet amino acid concentrations in patients affected by major depression and under fluvoxamine treatment. Neuropsychobiology. 1998; 37(3):124-9.

32. Coric V, Milanovic S, Wasylink S, Patel P, Malison R, Krystal JH. Beneficial effects of the antiglutamatergic agent riluzole in a patient diagnosed with obsessive-compulsive disorder and major depressive disorder.

Psychopharmacology. 2003;167(2):219-20.

\section{Publisher's Note}

Springer Nature remains neutral with regard to jurisdictional claims in published maps and institutional affiliations.
Ready to submit your research? Choose BMC and benefit from:

- fast, convenient online submission

- thorough peer review by experienced researchers in your field

- rapid publication on acceptance

- support for research data, including large and complex data types

- gold Open Access which fosters wider collaboration and increased citations

- maximum visibility for your research: over $100 \mathrm{M}$ website views per year

At $\mathrm{BMC}$, research is always in progress.

Learn more biomedcentral.com/submissions 